\title{
The Phonetic and Linguistic Environment of Third Singular Allomorphs in Parent Input
}

\author{
Colleen E. Fitzgerald, Rebecca C. Wettstein, Rebecca L. Ebert, Shannon M. Bridges \\ Department of Communication Sciences and Disorders, Bowling Green State University, Bowling Green, OH, United States
}

Purpose: The third person singular present tense morpheme (3s) has a protracted course of development for children with language disorders and for typically developing children compared to other phonetically or linguistically similar morphemes. This study's objective is to describe the phonetic and linguistic environment of 3s allomorphs in parent input.

Methods: Participants were 14 monolingual English-speaking parents of typically developing toddlers. Parents' allomorphs of 3s were examined for sentence position, allomorph type, coda of the inflected verb, onset of the following word, and the verb's input frequency both before and after the toddlers first used 3s.

Results: At both measurement points, the majority of instances of 3 s were sentence medial, took the form of an /s/ or /z/ allomorph, and both followed and preceded non-sibilant consonants. At the second measurement point, when emergence of 3s had begun for all children, parents inflected a significantly greater number of different verb types with 3s. Parents also inflected a greater number of verbs with low frequency in parent input at Time 2, as demonstrated through the calculation of a Weighted Verb Diversity score.

Conclusions: The findings of this study are both compatible with previous investigations of phonetic and linguistic environment and also build on those findings by examining the environment in greater detail. Speech-language pathologists could consider selecting target verbs that are intransitive and end with sibilants to increase the salience of the 3s morpheme for clinical populations at risk for delayed acquisition of the 3s morpheme.

Keywords: Parent input, Grammar, Morphology, Phonetics, Weighted Verb Diversity score

\section{INTRODUCTION}

There is a longstanding history of using spontaneous language samples to study the influence of parent input on children's early language development. The earliest of these investigations focused on the frequency of linguistic structures in parent input and their subsequent use in children's utterances [1,2]. Others focused on the complexity of morphemes used by parents and took into consideration the grammatical features represented by the morphemes (e.g., number, tense) [1,3]. More recent work has uncovered relationships between children's language outcomes and the intended function of parent utterances [4]. Children's grammatical development also appears to be influenced by the typology of the language spoken by parents and how particular linguistic structures are most often sequenced in parent input $[5,6]$.

One area of particular interest in the field has been how children use parent input to

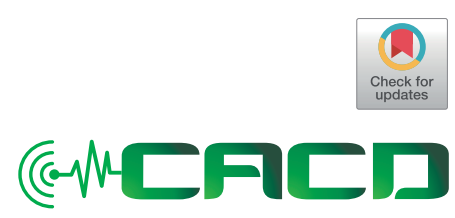

Received: June 29, 2018 Accepted: August 22, 2018

Correspondence:

Colleen E. Fitzgerald

Department of Communication Sciences and Disorders, Bowling Green State University, 247 Health and Human Services Building, Bowling Green, $\mathrm{OH} 43403$, United States Tel: +1-419-372-7182 Fax: +1-419-372-8089 E-mail: cefitzg@bgsu.edu

C 2018 The Korean Association of SpeechLanguage Pathologists

This is an Open Access article distributed under the terms of the Creative Commons Attribution NonCommercial License (http://creativecommons.org/ licenses/by-nc/4.0/) which permits unrestricted noncommercial use, distribution, and reproduction in any medium, provided the original work is properly cited. 
eventually cease the production of root infinitives in finite contexts (She like_it) [7-9]. Across languages, children initially fail to mark tense and agreement (i.e., finiteness) in contexts that require it in the adult grammar before gradually beginning to use tense and agreement morphemes correctly [10]. In English, the development of tense and agreement marking is particularly protracted, especially in comparison to Romance languages [11]. The extended nature of this period of development allows for researchers to examine gradual changes in the grammars of English-acquiring toddlers. Numerous investigations have attempted to explain the course of development for a suite of morphemes carrying information for finiteness [12,13]. In English, these morphemes include the copula and auxiliary BE (i.e., am, is, are, was, were), the auxiliary DO (i.e., do, does, did) and the third per son singular present tense morpheme (e.g., She runs).

The third person singular present tense morpheme (3s) has been given particular attention in the literature in part because of its relatively protracted course of development in English. Compared to other languages, both the emergence and mastery of agreement marking occur later in English acquisition $[10,14]$. Specifically, typically developing children acquiring English reach mastery of the 3s morpheme after age 4 [15]. Additionally, mastery of 3s occurs later in development than mastery of copula, another finiteness morpheme [13]. This slower rate of development has contributed to interest in the acquisition of the 3s. Furthermore, a variety of phonetic and linguistic factors distinguish $3 \mathrm{~s}$ from other grammatical morphemes and could explain the discrepancy in their acquisition rates. Below is both a review of the factors affecting 3s acquisition and the remaining gaps in our understanding of 3 s in parent input.

One explanation for the difficulty children experience with obligatory contexts for $3 s$ is its low frequency in parent input. The 3s morpheme is less frequent in the input when compared to other morphemes that carry agreement (i.e., copula and the auxiliaries BE and DO) [16]. Fitzgerald et al. [16] reported that parents talking to their toddlers use fewer than 10 instances of $3 \mathrm{~s}$ in $30 \mathrm{~min}$ of interaction, or, in approximately 300 utterances. By comparison, copula was used 64 times on average in the same samples. Likewise, 3s appears less frequently in input than plural -s [17]. Hsieh et al. [17] examined parents' verb inflections in conversations with their preschool-aged children with a diagnosis of specific language impairment [18]. They identified 55 verbs inflected with 3s compared to 285 plural -s inflections, demonstrating that plu- ral -s was five times more common than 3s. Furthermore, across the 18 most popular children's books at the time, only 19 uses of 3s occurred [18].

Additionally, $3 \mathrm{~s}$ is relatively difficult to acquire because it is more grammatically complex than other function morphemes. Complexity has long been established as an accepted explanation for the order of acquisition of grammatical morphemes [1]. The 3s morpheme carries values for three grammatical features: present tense, third person, and singular number. In comparison, many other grammatical morphemes only carry information for one feature. For example, -ed on verbs marks only past tense, -ing on verbs marks only progressive aspect, and -s on nouns marks only plural number. In order to productively use $3 \mathrm{~s}$, a child must have acquired knowledge of the tense, person, and number features and apply the correct values of these features (i.e., present, third, singular). It appears that children only use 3s correctly after first using copula is which carries the same values for the three features but is far more frequent in the input [13].

Next, there are three forms, or allomorphs, that 3 s manifests as depending on the sound preceding the morpheme. The allomorphs of 3s are /s/, /z/, and /oz/, with /s/ and /z/ occurring more frequently than /oz/ in English typology $[19,20]$. The /s/ allomorph is present after the voiceless phonemes /p, t, k, f, $\theta$ / (e.g., He sits). The allomorph /əz/ is present after all affricates and alveolar or palatal fricatives: /dz, t , s, z, J, z/ (e.g., He watches). Lastly, the allomorph $/ \mathrm{z} /$ is present after vowels and the remaining voiced consonants: /b, d, g, m, n, y, ठ, v, l/ (e.g., He runs). With 3 s manifesting as different allomorphs in their own unique phonetic contexts, it may be challenging for children to deduce when and how to use the appropriate allomorph, or even to attempt the 3s morpheme at all.

Further complicating the task of 3 s acquisition, the two allomorphs occurring most often in English, /s/ and /z/, have low acoustic salience because their spectral peaks are at a higher frequency than other sibilants (i.e., 4,000 Hz). Speech sounds with higher spectral peaks are more difficult to perceive. Additionally, $3 \mathrm{~s}$ is shorter in duration than plural -s, further reducing its comparative acoustic saliency [17].

Finally, children may find it challenging to articulate 3s. Children have particular difficulty when producing the /oz/ allomorph of plural -s, especially in the utterance medial position [21]. Because the allomorphs of 3s and plural -s are phonetically identical, children may have the same difficulties with 3s as they do with plural -s. Mealings and Demuth [22] reported the grammatical complexity of 3 s is not the only fac- 
tor contributing to its prolonged acquisition. The morpheme's sentence position and phonetic environment are also relevant to its protracted acquisition. Uses of the $3 s$ morpheme in the sentence medial position require more articulatory planning as a result of being followed by other sounds.

The majority of $3 \mathrm{~s}$ uses in spontaneous adult utterances directed to children are in the sentence medial position [20]. In a similar finding, Hsieh et al. [17] reported that $95 \%$ of occurrences of 3s in children's books they examined were in the sentence medial position. Furthermore, children's 3s accuracy in the sentence final position exceeded accuracy in the sentence medial position [22]. This finding provided confirmation of previous reports that children produce $3 \mathrm{~s}$ more accurately in the final position of sentences [23].

Despite the influence of sentence position on children's accuracy with 3s, phonetic environment factors may have an even greater impact on its production. Song et al. [23] investigated the role of coda complexity in children's 3s omissions. Children were more accurate in using $3 \mathrm{~s}$ in obligatory contexts when verbs' codas were singleton consonants rather than consonant clusters (e.g., cuts vs. wants). The coda complexity was a better predictor of 3s accuracy than other measures such as sentence position or children's mean length of utterance.

The current study is expected to contribute to our understanding of why the 3s morpheme has such a protracted course of development in English. It expands upon previous investigations of $3 \mathrm{~s}$ in input to children by investigating not only phonetic characteristics of the input, but also linguistic characteristics. Whereas other studies have reported on $3 \mathrm{~s}$ sentence position or phonetic characteristics of other morphemes, we characterize 3 s in the input by describing the phonetic context in greater detail. Specifically, although it is established that $3 s$ is acoustically shorter in duration than plural -s, other relevant phonetic characteristics such as the preceding sound (i.e., coda of the previous word) and following sound (i.e., onset of the next word) have not been quantified. The phonetic environment of 3s in parent input will be reported in terms of sentence position, allomorph type, and the preceding and following phonemes. Next, it is possible that children make use of 3s input differently when they hear the inflection on more practiced, highly frequent verbs than on rare, less familiar verbs. Therefore, this study will describe toddlers' experience with 3s relative to the inflected verb's rank frequency in the input. Lastly, parents adjust the complexity of their input in a bidirectional relationship as their children's grammatical abilities develop. Therefore, this study examines these phonetic and linguistic measures in parent input both early in children's grammatical development before they have attempted 3s and again later in development, when children optionally use 3s. The following research questions are addressed. Prior to and after children's emergence of $3 \mathrm{~s}$,

1. What is the phonetic environment of $3 \mathrm{~s}$ in parent input?

2. How frequent and diverse are the verbs that parents inflect with $3 \mathrm{~s}$ as measured by a weighted verb diversity score?

\section{METHODS}

\section{Participants}

Participants were 14 monolingual English-speaking parents of typically developing toddlers with language transcripts available in the Child Language Data Exchange System (CHILDES) [24]. Twelve of the children were part of the Manchester Corpus [25]. The other two children were Alex of the Providence Corpus [23] and Naomi from the Sachs Corpus [26]. Because samples were from multiple corpora, the recordings varied in length. To be able to compare the parents, only the first 500 utterances from each parent was examined in each transcript.

\section{Transcript selection}

Parent utterances were examined in the transcript immediately preceding the child's first use of 3 s (i.e., Time 1) and again after each child had begun using 3 s (i.e., Time 2). To select the Time 1 transcript, children's utterances were searched to identify their earliest use of 3s. For most children, the first use of 3 s could be identified with certainty because earlier samples without 3 s use were available. See Table 1 for participant ages at Time 1. When this was not the case (i.e., Anne, Gail, Joel, John, Nina, Warren), the earliest sample available was used for examining parent utterances. For Time 2, 32 months was used as a measurement point by which 13 of the 14 children had begun using 3s. For one child, Ruth, the 32-month sample was not used because her first use of 3 s was at 34 months. Therefore, her 33-month sample was used as her Time 1 transcript and her mother was excluded from Time 2 analyses for question 1 about phonetic environment. Ruth's mother was additionally excluded from question 2 analyses entirely. That question asked how parents differ in lexical diversity in response to their children's development and Ruth appears to be in the low average range. 
Table 1. Descriptive statistics for parent measures of linguistic environment

\begin{tabular}{lccccc}
\hline Child & $\begin{array}{c}\text { Child's } \\
\text { age }\end{array}$ & $\begin{array}{c}\text { Verb } \\
\text { types at } \\
\text { time 1 }\end{array}$ & $\begin{array}{c}\text { Verb } \\
\text { types at } \\
\text { time 2 }\end{array}$ & $\begin{array}{c}\text { WVD } \\
\text { score at } \\
\text { time 1 }\end{array}$ & $\begin{array}{c}\text { WVD } \\
\text { score at } \\
\text { time 2 }\end{array}$ \\
\hline Anne & 22 & 6 & 11 & 7,064 & 4,658 \\
Aran & 26 & 9 & 7 & 2,304 & 3,802 \\
Becky & 25 & 11 & 6 & 3,345 & 5,127 \\
Carl & 24 & 4 & 5 & 1,436 & 711 \\
Dominic & 22 & 5 & 13 & 1,043 & 15,649 \\
Gail & 23 & 9 & 13 & 3,033 & 6,765 \\
Joel & 23 & 1 & 10 & 30 & 3,474 \\
John & 23 & 8 & 6 & 1,842 & 3,967 \\
Liz & 24 & 3 & 5 & 1,384 & 588 \\
Nicole & 28 & 5 & 9 & 1,839 & 26,000 \\
Warren & 22 & 5 & 9 & 687 & 3,306 \\
Alex & 31 & 11 & 15 & 3,437 & 12,140 \\
Naomi & 31 & 1 & 5 & 40 & 1,336 \\
Mean & 24.92 & 5.92 & 8.77 & $2,114.15$ & $6,730.23$ \\
SD & 3.20 & 3.33 & 3.49 & $1,862.32$ & $7,239.73$ \\
\hline
\end{tabular}

Child's age, the age of the child in months at Time 1 before the emergence of $3 \mathrm{~s}$ (when possible); Verb Types, Number of different verb types inflected with 3s by the child's parent; WVD, weighted verb diversity.

\section{Coding}

All parent verbs inflected with 3s were coded by trained RA's following the conventions of the Systematic Analysis of Language Transcripts (SALT) [27]. Irregular uses of third person singular (i.e., does, says, has) were excluded because they undergo a vowel stem change distinguishing them from the regularly inflected verbs under investigation. Irregular uses made up a negligible portion of all third person singular present tense inflection. To determine the phonetic environment of $3 \mathrm{~s}$ in the input, values were identified for several measures for each parent 3 s use. First, inflected verbs were classified as occurring in either sentence medial (e.g., It fits in) or sentence final position (e.g., His head moves). Then, each use of 3s was coded for type of allomorph (i.e., /s/, /z/, or /oz/). Next, the coda (i.e., final consonant) of the inflected verb was identified. If a use of 3s was sentence medial, the onset (i.e., initial consonant) of the following word was also identified. For simplicity in referencing the final and initial sounds of words, we used the terms onset and coda even when a verb ends in a vowel (e.g., sees) or the following word begins with a vowel (e.g., fits on). Because we were concerned with the immediate neighboring environment of the 3s allomorphs, only the sounds immediately adjacent to the allomorphs were consid- ered rather than entire consonant clusters (e.g., goes straight). Place and manner of articulation were identified for codas and onsets to determine what proportion were alveolar sibilants like the allomorphs themselves.

The second research question required describing the linguistic environment of 3s. First, the number of different verbs inflected (i.e., verb types) and the total number of verbs inflected (i.e., verb tokens) were identified for each parent at Time 1 and Time 2. These values were compared using a Wilcoxon signed ranks test. Verb types were examined to understand the variety of verbs used. Verb token frequency was measured to establish the number of caregiver uses of a particular verb type in one sample. Next, counts were tallied for each parent verb type inflected for 3s. This was done to characterize which verbs that parents as a group most often inflected with 3s and to detect any changes over time. Then, for the verbs that parents inflected, rank frequency in parent input was determined. Each verb was given a rank out of all words in caregiver input based on Li \& Shirai's [28] compilation of all words spoken to English learning children in the CHILDES database [24,28]. Lastly, to examine the linguistic complexity of caregiver input prior to and during children's acquisition of 3s, the frequency of verbs in relation to their rank in caregiver input were investigated using a measure we introduce in this paper, the Weighted Verb Diversity (WVD) score. The WVD score was obtained by multiplying the verb's rank in caregiver input (i.e., rank multiplier) by the number of token uses of that verb. For example, if a parent inflected six different verbs with 3 s in one language sample, each verb's rank in the input was multiplied by the number of times the parent inflected that verb and those six multiplication products were summed to yield the WVD score for that parent's sample. See Table 2 for an example calculation.

Additionally, counts were tallied for each parent verb inflected for $3 \mathrm{~s}$ in order to characterize which verbs are most often inflected and to discuss this in terms of overall verb frequency in both parent and child utterances. Finally, we compared these measurements at the child's initial 3s use with the 32-month language sample.

\section{Reliability}

Coding reliability was obtained through consensus. All coding decisions and calculations were first completed independently by a trained RA before being checked by a second trained RA. 
Table 2. Example calculation of WVD for all verbs inflected by one parent

\begin{tabular}{|c|c|c|c|c|c|c|c|}
\hline \multicolumn{4}{|c|}{ Time 1} & \multicolumn{4}{|c|}{ Time 2} \\
\hline Verb type & Rank multiplier & Token frequency & WVD score & Verb type & Rank multiplier & Token frequency & WVD score \\
\hline Like & 33 & 1 & 33 & Bump & 1,235 & 1 & 1,235 \\
\hline Come & 64 & 1 & 64 & Hurt & 318 & 2 & 636 \\
\hline Go & 30 & 4 & 120 & Laugh & 1,718 & 1 & 1,718 \\
\hline Need & 161 & 4 & 644 & Look & 59 & 2 & 118 \\
\hline Turn & 173 & 1 & 173 & Make & 103 & 3 & 309 \\
\hline Match & 1,657 & 1 & 1,657 & Stop & 301 & 1 & 301 \\
\hline Eat & 112 & 2 & 224 & Seem & 1,602 & 1 & 1,602 \\
\hline \multirow[t]{7}{*}{ Look } & 59 & 2 & 118 & Want & 42 & 2 & 84 \\
\hline & & & & Work & 235 & 1 & 235 \\
\hline & & & & Go & 30 & 1 & 30 \\
\hline & & & & Know & 27 & 2 & 54 \\
\hline & & & & Love & 282 & 1 & 282 \\
\hline & & & & Need & 161 & 1 & 161 \\
\hline & & & ne $1 \mathrm{WVD}=3,033$ & & & & Time 2 WVD =6,765 \\
\hline
\end{tabular}

WVD, weighted verb diversity.

\section{RESULTS}

In order to address the first question, the measures of the phonetic environment of 3s in parent input including sentence position, allomorph type, coda manner, onset manner and place of articulation were examined. Across all 14 parents at Time 1, 3s was used 183 times $(M=13.07, S D=7.33)$ and similarly, was used 192 times at Time $2(M=14.77, S D=7.68)$. The first aspect of phonetic environment examined was sentence position. At both measurement points, more 3s uses were sentence medial than sentence final (see Table 3). The next measure of 3s was allomorph type. The most common allomorphs of $3 \mathrm{~s}$ at Time 1 and Time 2 were /s/ and /z/. At both time points, the third allomorph, /əz/, accounted for a negligible portion of all allomorphs. The next aspect of phonetic environment explored was the sound immediately before the 3 s (i.e., the coda on the inflected verb). This sound was typically a consonant. The most common consonant codas at Time 1 and Time 2 were voiceless non-sibilants (i.e., / $\mathrm{k}$, t, p/; see Table 4). The allomorph /z/ could result from two coda manners: either no coda (i.e., final sound was a vowel) or a voiced non-sibilant (e.g., /b/, /d/, etc.; see Figure 1). Voiced non-sibilant codas were the more common source of the /z/ allomorph. Sibilant consonant codas counted for a negligible portion of codas at both Time 1 and Time 2. The next aspect of phonetic environment examined was the sound
Table 3. Phonetic environment values for all measures as a proportion of $3 \mathrm{~s}$ uses across parents

\begin{tabular}{llll}
\hline & & Time 1 & Time 2 \\
\hline Allomorph & /s/ & 0.514 & 0.422 \\
& /z/ & 0.470 & 0.568 \\
Sentence position & /az/ & 0.016 & 0.010 \\
& Medial & 0.902 & 0.854 \\
Coda & Final & 0.098 & 0.146 \\
& Voiceless Non-sibilant & 0.530 & 0.417 \\
& Voiced Non-sibilant & 0.273 & 0.370 \\
Onset place of & Sibilant & 0.005 & 0.010 \\
articulation & Open syllable & 0.191 & 0.203 \\
& Alveolar & 0.486 & 0.406 \\
& Interdental & 0.156 & 0.117 \\
& Velar & 0.073 & 0.086 \\
& Palatal & 0.110 & 0.063 \\
\hline
\end{tabular}

Coda, the coda of the inflected verb, or, the sound preceding the 3s inflection including vowels (i.e., open syllables); Onset, the onset of the word following the 3 s inflection for medial instances only.

following the inflected verb. Nearly two-thirds of sentencemedial 3s allomorphs preceded a consonant onset at both Time 1 and Time 2. However, these were rarely sibilant onsets, so it was not common for allomorphs to be followed by a consonant sharing the same manner, which could have limited perceptibility. At both time points, the place of articulation of 
Table 4. Most common coda and onset phonemes across all data in order of frequency of use

\begin{tabular}{|c|c|c|c|}
\hline & & Time 1 & Time 2 \\
\hline \multirow[t]{3}{*}{ Coda manner } & Voiceless Non-sibilant & $/ k, t /$ & $/ k, t /$ \\
\hline & Voiced Non-sibilant & $/ \mathrm{d}, \mathrm{m} /$ & $/ \mathrm{d}, \mathrm{m}, \mathrm{n} /$ \\
\hline & Sibilant & $|z|$ & $|z|$ \\
\hline \multirow[t]{4}{*}{ Onset place of articulation } & Alveolar & $/ t, l, d, s /$ & $/ t, I, s /$ \\
\hline & Interdental & / $\theta$, д/ & /ð/ \\
\hline & Velar & /g, k, w/ & $/ g, w, k /$ \\
\hline & Palatal & $/ r, j, d_{3}, j /$ & $/ j, r, t g /$ \\
\hline
\end{tabular}

the onset was alveolar nearly as often as it was all other places of articulation combined.

The second research question explored the linguistic complexity of parent 3s prior to and during children's 3s acquisition for the 13 parents with data at both measurement points (i.e., excluding Ruth's mother). This was first determined by identifying how many different verbs each parent used at each measurement point (i.e., verb types). Parents inflected a significantly greater number of verb types at Time $2(M=8.77, S D=$ 3.49) than they did at Time $1(M=5.92, S D=3.33 ; Z=-2.08, p=$ 0.037 ) as compared with a Wilcoxon signed ranks test. Nine of the 13 parents inflected a greater number of different verbs at Time 2 . Despite this, as a group, the parents used only slightly more total 3s inflections at Time 2 (192 tokens; $M=14.77, S D=$ 7.68) than at Time 1 (168 tokens; $M=12.92, S D=7.91$ ) even though the children were all using the morpheme in their own utterances. Furthermore, this difference did not reach significance $(Z=-0.88, p=0.379)$. Four of the 13 parents did not demonstrate any increase in use of 3 s inflections over time.

The majority of inflected verb types were inflected with $3 \mathrm{~s}$ only once. At both measurement points, inflected verbs that were low in frequency in the language (e.g., wobble, prove, scrape) were generally used just a single time across all parents. The most commonly inflected verbs were also the verbs that are most frequent in the language overall (i.e., go, need, look, want, come).

Next, for each verb inflected by a parent, rank frequency was used in combination with how often the verb was inflected by a parent. Rank frequency was multiplied by the number of times that verb was inflected (i.e., tokens for an individual parent). The resulting product yielded a WVD score for each verb for each parent and Time 1 and Time 2. Parents' WVD increased significantly between Time 1 and Time 2 (i.e., $M=$ $2,114, S D=1,862$ vs. $M=6,730, S D=7,239 ; Z=2.46, p=0.007$ ).

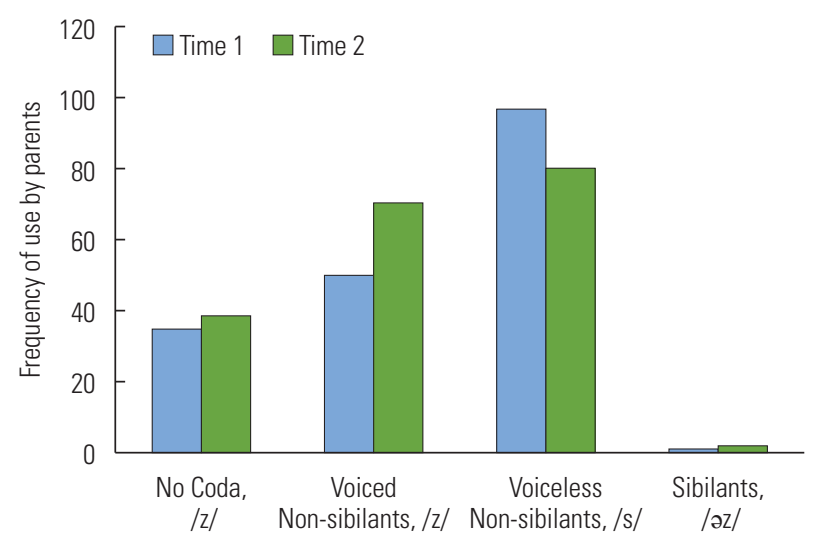

Figure 1. Distribution of verb coda manner and allomorph type.

\section{DISCUSSION AND CONCLUSIONS}

This study has the potential to shed light on numerous previous findings. First, the third person singular morpheme is late-acquired in typical development when compared to the same inflection across languages and when compared to other English morphemes. It is also rare in parent input and in children's books. However, the phonetic environment of parent 3s allomorphs and their relationship to word frequency in the language had not yet been explored in the way presented here.

The first research question examined the phonetic environment of 3s in maternal input both before and during children's acquisition of 3s. The majority of 3s uses were in the medial sentence position and were usually /s/or/z/ allomorphs, confirming results from previous studies $[17,19,20]$. However, beyond replicating this previous finding, the current study contributed to the extant literature by separately examining the two environments that create the /z/ allomorph, verbs ending in vowels and verbs ending in voiced non-sibilants. This was important to quantify because children may process the allomorph /z/ differently based on the phonetic context, especially considering the first of the two environments (i.e., no coda) could result in the allomorph having more acoustic salience. The third singular inflection followed an open syllable only a limited number of times. We expect this type of environment, where a vowel precedes 3s similar to the structure of the /oz/ allomorph, could help facilitate processing of 3s due to the neutrality of the vowel. The presence of the vowel may make the allomorph /z/ following the coda more salient and therefore more noticeable. Future work could investigate this possibility in an experimental design ex- 
posing children to novel 3s-inflected verbs with and without codas.

The next notable finding of this study was that when the inflected verb was in the sentence medial position, the most frequent manner of the following phoneme was a sibilant. Since the allomorphs themselves are sibilants, we predict this may make segmenting the $3 \mathrm{~s}$ from the inflected verb more difficult, as the child may perceive the sibilant sound to simply be the onset of the following word (e.g., She needs some). On the other hand, occurrences of sibilant sounds before the 3s may be particularly beneficial, as these lead to the manifestation of the rarely used /oz/ allomorph, which previous work has shown children more readily perceive. In sum, apart from sibilant codas, a phonetic environment with phonemes that are too similar to the /s/ and /z/ allomorphs, could cause difficulty for children attempting to segment $3 s$ morphemes in connected speech.

Although the phonetic environment of 3s in parent input to toddlers appears to be constrained by the typology of English, interesting changes occurred in linguistic complexity of parent 3s inflection over the course of their children's 3s development. First, before children had begun using 3s allomorphs in their own utterances, parents inflected relatively few different verb types with $3 \mathrm{~s}$. The finding is compatible with prior work demonstrating that parents increase lexical diversity as children's abilities grow [29]. It is possible that as parents perceived that their children could understand more words, they inflected a greater variety of verbs with $3 s$. Huttenlocher, Waterfall, Vasilyeva, Vevea, and Hedges [30] demonstrated that children's syntactic diversity does not predict similar measures in their parents' input. This was taken as evidence that although mutual directionality exists for the vocabulary domain, this is not the case for syntax. Parents' verb type diversity with 3 s increased over time, but their syntactic complexity in terms of the number of 3s inflections did not significantly increase over time. The children's progress in using 3s did not prompt an increase in their parents' use of the morpheme. Thus, the results presented here are compatible with previous work demonstrating that parents use more lexical diversity in response to children's development but not more syntactic complexity.

The next analysis of linguistic complexity explored the frequency in the English language of the verbs that parents inflected with 3s. Song et al. [23] investigated the influence of lexical frequency on children's accuracy at producing 3s. They reported that verb frequency in the input could not explain whether children would inflect the verb with $3 \mathrm{~s}$. The present study instead examined the input frequency of the verbs that parents inflected rather than the verbs that children attempted. Increasingly, the verbs that parents inflected with $3 \mathrm{~s}$ were low frequency in the input. Further, parents' weighted verb diversity scores reflected not only how rare their 3 s inflected verbs were, but also how many times they used 3s on those less frequent verbs. Although parents inflected fewer total verbs with 3 s at Time 2, they used less frequent verbs when they did use the inflection. As a result, most parents' (i.e., 10 of 13) WVD scores increased from Time 1 to Time 2.

Notably, when parents used high frequency verbs, those verbs tended to be used as state verbs such as want or need. Verbs that can be used as action verbs were predominantly used as state verbs instead (e.g., It goes here, not It goes fast). This tendency could have implications for acquisition of $3 \mathrm{~s}$ as children tend to notice and comment on actions when they are near the age these participants were at Time 1 [31].

\section{Limitations}

This study was a descriptive, exploratory investigation into the nature of $3 \mathrm{~s}$ allomorphs in parent input. We are limited in our ability to generalize our findings to the general population, first because parents used different dialectal varieties of English, and second be cause demographic information was not available for all parents. We are therefore limited in interpreting results in light of the families' socioeconomic status (SES), which is related to child vocabulary size and word diversity [32].

Additionally, we do not know how our measures of phonetic context and linguistic diversity relate to children's later 3 s use. A common way to measure children's knowledge of a morpheme is through an accuracy score. However, these can be unreliable if the denominator, representing obligatory contexts, is not high enough. The children of the participating parents were too young when the availability of transcripts ended to have enough contexts for a reliable accuracy score.

\section{Clinical implications and future directions}

The findings of this study may reveal yet another reason that the development of the 3s morpheme is relatively protracted in English, especially for children with developmental language disorders. The morpheme is difficult to acquire not only because of its rarity in the input, its grammatical complexity, and its low phonetic salience, but also $3 \mathrm{~s}$ is most often neighbored by sounds that may further reduce its acoustic salience. About half of 3s occurrences immediately followed an 
alveolar consonant, but most of these were either $n, t, d$, or $l$ and not the sibilants $s$ and $z$ which would result in the use of the /oz/ allomorph. Instead, these non-sibilant consonant codas may obscure the presence of 3s because they share the same place of articulation. Because of this possibility, when selecting treatment targets for therapy, clinicians may want to consider using verbs that end in non-alveolar consonants if they use verbs with codas at all. That is, these results also point to a clinical recommendation to consider whether target verbs must have a coda. When 3s allomorphs inflect a verb with no coda, it's likely that the allomorph itself has greater duration, thereby increasing its salience. Additionally, describing the environment of $3 \mathrm{~s}$ in the input could hold implications for facilitating $3 \mathrm{~s}$ with other clinical populations. Children with hearing impairment are late to acquire $3 s$ [20,33]. We expect the phonetic environment of $3 \mathrm{~s}$ in the input to be particularly relevant for this population given their limited auditory access and the effects of hearing aid bandwidth compression on high frequency sibilants.

To determine whether there is empirical support for particular environments being more salient in the input, a follow up study is underway to measure the acoustic factors of $3 \mathrm{~s}$ in various phonetic environments. We have created a children's book to measure the acoustic duration, intensity, and spectral peaks of 3s allomorphs to include instances of 3s in a variety of phonetic environments [34]. The book contains 31 instances of 3s. As much as possible, sentences were strategically designed to represent the phonetic and linguistic environments of 3s we believe to increase saliency -- after vowels (e.g., "sees it"), with the /əz/ allomorph (e.g., "pushes"), or utterance final (e.g., "There he goes"). Since we do not know which contexts facilitate salience, the next investigation aims to validate the clinical decisions made in designing the children's book. Studying the acoustic factors of 3s will shed light on whether its position between vowels vs. consonants creates greater saliency in the way that sentence position and allomorph type have been shown to. This will help us understand how manipulating these factors can make better therapy tools for children.

Future work is needed to understand the clinical implications of parents inflecting a greater variety of infrequent verbs as children's productions of 3s increased. It is unknown whether hearing $3 \mathrm{~s}$ in the input on rare verbs is helpful to children. It is possible that these instances of $3 \mathrm{~s}$ on rare verbs may be particularly helpful to children because the transitional probability between the verb stem and the 3s morpheme is lower on rare verbs than on high frequency verbs. Alternatively, being familiar with the verb already might provide an advantage for the child. For example, if a child is familiar with the word open, hearing opens might be especially beneficial to the acquisition of $3 \mathrm{~s}$ because the morpheme boundary is readily identifiable. On the other hand, if the child is not familiar with the inflected verb (e.g., That suits you fine), the relatively lower transitional probability may not help in identifying the 3 s allomorph because the child might parse the multimorphemic word as a single morpheme. If a future study revealed a relationship between input frequency of inflected verbs and children's propensity to use the 3s inflection later, then clinicians could strategically select target verbs using rank frequency as a guide.

\section{CONCLUSIONS}

The findings of this investigation provide further reasons that the third person singular morpheme is especially difficult to acquire compared to other English morphemes. The phonetic contexts in which it naturally appears in the English typology may reduce its salience for children acquiring grammar. The limited number of different verbs parents inflect with 3s may further protract its development. Speech-language pathologists can take advantage of the information provided here to develop therapy materials for children struggling to acquire English grammar. By choosing verbs for 3s inflection that are intransitive (i.e., more likely to be utterance final) and that end with sibilants (i.e., yielding /oz/; brushes, budges), SLP's can facilitate the salience and possibly the acquisition of $3 \mathrm{~s}$ for their clients.

\section{ACKNOWLEDGMENTS}

Portions of this article were previously presented at the American Speech-Language Hearing Association convention in Los Angeles, California (November, 2017). This research was supported by funds from the College of Health and Human Services Linda Petrosino PILLARS Fund, the BGSU Department of Communication Sciences and Disorders, and the BGSU Graduate College. The authors would like to acknowledge the assistance of Shannon Damschroder, Amy Smith, Amanda Spangenberg, and Bailey Zalar in transcript processing and data coding. Finally, we are grateful to the participating families and to the contributors of the Manchester, Providence, and Sachs corpora from CHILDES that were analyzed in this study. 


\section{REFERENCES}

1. Brown R. A first language: the early stages. Harvard U. Press; 1973.

2. Newport E, Gleitman H, Gleitman L. Mother, I'd rather do it myself: some effects and non-effects of maternal speech style. In: Snow CE \& Ferguson CA, editors. Talking to children: language input and acquisition. Cambridge: Cambridge University Press, 1977. p. 109-149.

3. De Villiers JG, De Villiers PA. A cross-sectional study of the acquisition of grammatical morphemes in child speech. J Psycholinguist Res. 1973;2:267-278.

4. Hoff E. How social contexts support and shape language development. Dev Rev. 2006;26:55-88.

5. Tomasello M. The usage-based theory of language acquisition. In Bavin EL, editor. The Cambridge handbook of child language. Cambridge University Press, 2005. p. 69-87.

6. Yang CD. Knowledge and learning in natural language. Oxford University Press on Demand; 2002.

7. Freudenthal D, Pine JM, Gobet F. Simulating the referential properties of Dutch, German, and English root infinitives in MOSAIC. Lang Learn Dev. 2009;5:1-29.

8. Rispoli M, Hadley P. Input effects on the acquisition of finiteness. In Chu C, Coughlin C, Prego BL, Minai U, Tremblay A, editors. Proceedings of the 5th Generative Approaches to Language Acquisition North America. Somerville, MA: Cascadilla Press, 2014. p. 121-127.

9. Wexler K. Optional infinitives, head movement and the economy of derivations. Verb movement. 1994; p. 305-350.

10. Guasti MT. Language acquisition: the growth of grammar. Cambridge, MA: MIT press; 2017.

11. Legate JA, Yang C. Morphosyntactic learning and the development of tense. Lang Acquis. 2007;14:315-344.

12. Bedore LM, Leonard LB. Specific language impairment and grammatical morphology: a discriminant function analysis. J Speech Lang Hear Res. 1998;41:1185-1192.

13. Rispoli M, Hadley PA, Holt JK. Sequence and system in the acquisition of tense and agreement. J Speech Lang Hear Res. 2012;55: 1007-1021.

14. Yang CD. Universal Grammar, statistics or both?. Trends Cogn Sci. 2004;8:451-456.

15. Rice ML, Wexler K, Hershberger S. Tense over time: the longitudinal course of tense acquisition in children with specific language impairment. J Speech Lang Hear Res. 1998;41:1412-1431.

16. Fitzgerald CE, Hadley PA, Rispoli M. Are some parents' interaction styles associated with richer grammatical input?. Am J Speech Lang Pathol. 2013;22:476-488.

17. Hsieh L, Leonard LB, Swanson L. Some differences between English plural noun inflections and third singular verb inflections in the input: the contributions of frequency, sentence position, and duration. J Child Lang. 1999;26:531-543.

18. Conti-Ramsden G, Dykins J. Mother-child interactions with language-impaired children and their siblings. Int J Lang Commun Disord. 1991;26:337-354.

19. Berko J. The child's learning of English morphology. Word. 1958; 14:150-177.

20. Koehlinger K, Van Horne AO, Oleson J, McCreery R, Moeller MP. The role of sentence position, allomorph, and morpheme type on accurate use of s-related morphemes by children who are hard of hearing. J Speech Lang Hear Res. 2015;58:396-409.

21. Mealings KT, Cox F, Demuth K. Acoustic investigations into the later acquisition of syllabic-es plurals. J Speech Lang Hear Res. 2013;56:1260-1271.

22. Mealings KT, Demuth K. The role of utterance length and position in 3-year-olds' production of third person singular -s. J Speech Lang Hear Res. 2014;57:484-494.

23. Song JY, Sundara M, Demuth K. Phonological constraints on children's production of English third person singular -s. J Speech Lang Hear Res. 2009;52:623-642.

24. MacWhinney B. The CHILDES project: tools for analyzing talk: Volume I: Transcription format and programs, volume II: The database. 3rd ed. Mahwah, NJ: Lawrence Erlbaum Associates; 2000.

25. Theakston AL, Lieven EV, Pine JM, Rowland CF. The role of performance limitations in the acquisition of verb-argument structure: an alternative account. J Child Lang. 2001;28:127-152.

26. Sachs J. Talking about the there and then: the emergence of displaced reference in parent-child discourse. Children's language. 1983;4:1-28.

27. Miller JF, Iglesias, A. SALT: systematic analysis of language transcripts [Computer software]. Madison, WI: Language Analysis Laboratory, Waisman Center, University of Wisconsin. 2015.

28. Li P, Shirai Y. The acquisition of lexical and grammatical aspect. Berlin \& New York: Mouton de Gruyter; 2000.

29. Huttenlocher J, Vasilyeva M, Waterfall HR, Vevea JL, Hedges LV. The varieties of speech to young children. Dev Psychol. 2007;43: 1062.

30. Huttenlocher J, Waterfall H, Vasilyeva M, Vevea J, Hedges LV. Sources of variability in children's language growth. Cogn Psychol. 2010;61:343-365.

31. Bloom L. Language development: form and function in emerging grammars. Cambridge, MA: MIT Press; 1970.

32. Hoff-Ginsberg E. Maternal speech and the child's development of syntax: a further look. J Child Lang. 1990;17:85-99.

33. Norbury CF, Bishop DV, Briscoe J. Production of English finite verb morphology: a comparison of SLI and mild-moderate hearing impairment. J Speech Lang Hear Res. 2001;44:165-178.

34. Ebert RL. Constructing a grammatically enriched children's book. Bowling Green State University, Bowling Green, Ohio. Unpublished honors capstone. 2017. 